\section{Commentary: Now I think I know the answer}

\section{Brendon M. Stiles, MD}

In the current issue of the Journal, Tang and colleagues ${ }^{1}$ from the Cleveland Clinic elegantly compare the demographics and outcomes of patients with lung cancer based on their smoking status. They divide the patients into never- versus eversmokers. Understanding the demographics and outcomes of never-smokers with lung cancer is increasingly important. Although overall lung cancer incidence and mortality finally appear to be on a downward trend, we have seen a curious rise in absolute cases of lung cancer in never-smokers. At our institution, they now comprise almost $30 \%$ of all of the patients who we operate on for lung cancer. ${ }^{2}$ It isn't clear whether there is an actual increased incidence of lung cancer in these patients or whether we are simply now better at diagnosing it, but it is clear that lung cancer in never-smokers is a public health issue. Indeed, as the authors point out, non-small cell lung cancer in never-smokers is the 7th-leading cause of cancer deaths in the United States. It is therefore critical that we understand the disease and turn our attention to it.

In the Cleveland Clinic series, $11 \%$ of their surgical patients with lung cancer were never-smokers. Not surprisingly, these patients were more likely female, had better lung function, fewer comorbidities, and were more likely to have adenocarcinoma. We and others have observed the same demographic features. What is remarkable about this manuscript, however, is the difference in survival within constrained stage groupings and the puzzling finding that stage I never-smokers do much better ( $96 \%$ vs $78 \% 5$-year survival), whereas stage II never-smokers do much worse ( $54 \%$ vs $78 \% 5$-year survival) than matched ever-smokers. That finding made all of the reviewers of the paper pause,

From the Department of Cardiothoracic Surgery, Weill Cornell Medicine, New York-Presbyterian Hospital, New York, NY.

Disclosures: The author reported consulting/speaker fees from AstraZeneca, Pfizer, Bristol Myers Squibb, Ribon Therapeutics, Gala Therapeutics, WebMD, and Medtronic. He is on the Board of the Lung Cancer Research Foundation. His spouse receives salary/stock from Pfizer and PPD.

The Journal policy requires editors and reviewers to disclose conflicts of interest and to decline handling or reviewing manuscripts for which they may have a conflict of interest. The editors and reviewers of this article have no conflicts of interest

Received for publication April 5, 2020; revisions received April 5, 2020; accepted for publication April 7, 2020; available ahead of print April 18, 2020.

Address for reprints: Brendon M. Stiles, MD, 525 East 68th St, Greenberg Pavilion, M404, New York, NY 10065 (E-mail: Brs9035@med.cornell.edu).

J Thorac Cardiovasc Surg 2021;161:1918-9

0022-5223/ $\$ 36.00$

Copyright $₫ 2020$ Published by Elsevier Inc. on behalf of The American Association for Thoracic Surgery

https://doi.org/10.1016/j.jtcvs.2020.04.033

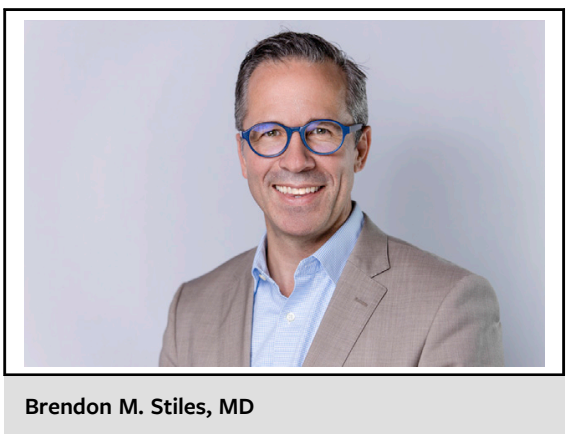

CENTRAL MESSAGE

Lung cancer in never-smokers is clinically and biologically distinct from that in ever-smokers.

myself included. But when I looked back on our own series, I found that the differences in stage I and stage II were almost identical to those described here. ${ }^{2}$ Perhaps I wasn't observant enough to make much of it at that point in time or considered it an anomaly due to relatively small numbers of patients. In the current series, however, the authors carefully characterized the groups and applied the rigorous statistical models that their group is known for. The results held up.

So what should we make of this surprising finding and how can we explain it? It certainly must speak to some difference in biology of the disease, as suggested by the authors. Tang and colleagues were unable to include molecular subtyping of tumors in their analysis, understandable given that many of the patients were operated on before routine molecular testing of early-stage tumors at their institution. It is well understood that never-smokers have significantly greater rates of actionable driver mutations and rearrangements than ever-smokers. Perhaps when stage I disease is completely resected and assured with an oncologically sound operation, we have little to worry about with regard to cancer recurrence or death in never-smokers. The crux then is what happens to stage II and greater never-smokers. During the time period of the study, these patients were likely treated with adjuvant chemotherapy and many likely with systemic chemotherapy upon recurrence. It is not a stretch to think that those with unique molecular alterations are perhaps less likely to respond to chemotherapy, as suggested by the authors. And perhaps those with molecular drivers and nodal disease were more likely to have occult metastatic disease, including brain metastases. The preoperative staging and patterns of failure are not described by the authors. Either way, this manuscript should encourage us to more carefully study locally advanced disease in never-smokers. In my opinion, tumors in all of these patients should undergo molecular 
testing. Perhaps targeted neoadjuvant or adjuvant strategies will help. Large-scale studies are underway or planned, including the Lung Cancer Mutation Consortium 4 PROMISE study. ${ }^{3}$ The comparatively poor outcome found in stage II never-smokers in the current study should provide the impetus for enrollment into that study and would seem to answer an important question. Non-small cell lung cancer in never-smokers is a very different disease.

\section{References}

1. Tang A, Ahmad U, Toth AJ, Bourdakis N, Raja S, Raymond DP, et al. Non-smal cell lung cancer in never and ever-smokers: is it the same disease? J Thorac Cardiovasc Surg. 2021;161:1903-17.e9.

2. Stiles BM, Rahouma M, Hussein MK, Nasar A, Nguyen AB, Harrison S, et al Never smokers with resected lung cancer: different demographics, similar survival. Eur J Cardiothorac Surg. 2018;53:842-8.

3. Blumenthal GM, Bunn PA, Chaft JE, McCoach CE, Perez EA, Scagliotti GV, et al Current status and future perspectives on neoadjuvant therapy in lung cancer. $J$ Thorac Oncol. 2018;13:1818-31.
See Article page 1903.

\section{Commentary: Smoke or fire? Resected lung cancer in never-smokers}

\author{
Chuong D. Hoang, MD
}

Apparently, there is a growing proportion of never-smokers, those self-identified as someone with fewer than 100 cigarettes smoked in their lifetime, afflicted with non-small cell lung cancer (NSCLC) despite its known strong causal association to cigarette smoking. ${ }^{1}$ However, the clinical distinction between these patient groups of never-smokers compared with ever-smokers, especially in terms of risk factors, has been difficult to precisely define.

In this issue of the Journal, Tang and colleagues ${ }^{2}$ perform a retrospective analysis comparing never-smokers with ever-smokers using advanced, more accurate statistical methods that include group matching based on a balancing score and employment of machine learning to individually characterize the impact of specific cancer characteristics (ie, tumor size, etc). Patients in this single institution report all underwent surgical resection as part of treatment. Interestingly, when survival is assessed by tumor-node-

\footnotetext{
From the Thoracic Surgery Branch, National Cancer Institute-National Institutes of Health, Center for Cancer Research, and The Clinical Center, Bethesda, Md. Disclosures: Author has nothing to disclose with regard to commercial support. Received for publication March 22, 2020; revisions received March 22, 2020; accepted for publication March 23, 2020; available ahead of print April 10, 2020. Address for reprints: Chuong D. Hoang, MD, Thoracic Surgery Branch, National Cancer Institute-National Institutes of Health, Center for Cancer Research, and The Clinical Center, 10 Center Dr, mail code 1201, Room 4-3940, Bethesda, MD 20892 (E-mail: chuong.hoang@nih.gov).

J Thorac Cardiovasc Surg 2021;161:1919-20 0022-5223/\$0.00

Published by Elsevier Inc. on behalf of The American Association for Thoracic Surgery

https://doi.org/10.1016/j.jtcvs.2020.03.096
}

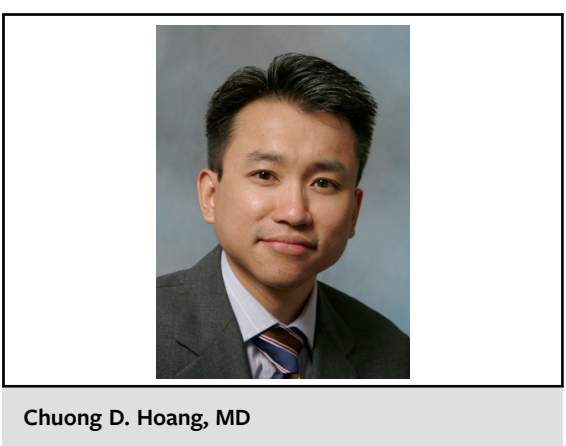

CENTRAL MESSAGE

Among never-smokers, NSCLC is an important problem, yet the clinical profile of this patient population and their specific outcomes remain to be fully elucidated.

metastasis stage, there appears to be paradoxical worse survival of never-smokers assigned to more advanced pathologic stage, whereas the same category of patients enjoyed better survival in early pathologic stage. This phenomenon was observed in a subset of 90 matched pairs of patients who were stage I and in a subset of 44 matched pairs of patients who were stage II. The authors infer, overall, that smoking status should be incorporated into future NSCLC staging systems to improve prognostic performance as cigarette smoking seems to impart unique impacts.

In contradistinction to the findings here, the previous

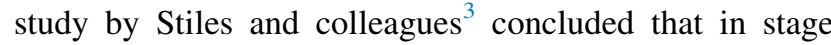
and propensity-matched cohorts of never-smokers and smokers the overall survival was similar, not distinct. They reported statistical nonsignificance in cancerspecific survival rates among never-smoker versus smokers $(\mathrm{N}=498$ patient in each matched group). Looking at 